\title{
Simultaneous femoral derotation osteotomy and selective dorsal rhizotomy in children with spastic cerebral palsy: A prospective follow-up of 3 cases
}

Hanne Schreurs ${ }^{1}$, Catherine Huenaerts ${ }^{2}$, Kaat Desloovere ${ }^{2,3}$, Els Ortibus ${ }^{4,5}$, Sandra Prinsen ${ }^{6}$, Petra Pauwels ${ }^{7}$, Bart Nuttin ${ }^{8,9}$, Philippe De Vloo $^{8,9}$ and Anja Van Campenhout ${ }^{4,6 *}$

${ }^{1}$ Faculty of medicine, KU Leuven, Leuven, Belgium

${ }^{2}$ Clinical Motion Analysis Laboratory, University Hospital Leuven, Leuven, Belgium

${ }^{3}$ Department of Rehabilitation Sciences, KU Leuven, Leuven, Belgium

${ }^{4}$ Department of Development and Regeneration, KU Leuven, Leuven, Belgium

${ }^{5}$ Department of Pediatric Neurology, University Hospital Leuven, Leuven, Belgium

${ }^{6}$ Department of Orthopaedics, University Hospital Leuven, Leuven, Belgium

${ }^{7}$ Department of Rehabilitation, University Hospital Leuven, Leuven, Belgium

${ }^{8}$ Department of Neurosurgery, University Hospital Leuven, Leuven, Belgium

${ }^{9}$ Department of Neurosciences, KU Leuven, Leuven, Belgium

\begin{abstract}
Background: Both spasticity and high femoral anteversion are common features in children with cerebral palsy (CP). Previous studies have shown that children with these symptoms benefit from both a selective dorsal rhizotomy (SDR) to lower tone in the muscles in the lower limb and from a femoral derotation osteotomy (FDO) to correct lever arms. Multiple procedures and a long rehabilitation period may be challenging for a young child. Therefore, both interventions have been organized simultaneously in selected indications at the University hospital of Leuven since 2016.
\end{abstract}

Method: Data of the first patients who underwent simultaneous SDR-FDO with a two year longitudinal follow-up were studied. Three-dimensional gait analysis were obtained preoperative, at short (1 year) and medium ( 2 year) term postoperative to define the gait profile score (GPS) and specific gait features. Their medical history, postoperative complications, rehabilitation period and functional scales were described. Furthermore, these data were compared with a group of children with $\mathrm{CP}$ who underwent FDO prior to SDR and with a group who underwent SDR-only.

Results: The GPS significantly improved in the three cases, exceeding the minimal clinically important difference. The result of the three patients equalized the group who underwent FDO and SDR at different time points. Moreover, a large decrease in their excessive anterior pelvic tilt, an improvement in hip extension and rotation and improvement of ankle and knee kinematics were seen. Functional mobility scale improved in all three patients. No serious events were reported. Only a small number of grade I and II complications, according to the Modified Clavien-Dindo system, were observed.

Interpretation: In children who need both spasticity reduction and bony malformation correction, simultaneous FDO and SDR is a safe procedure that yields a significant improvement in gait with a reduction of hospital admissions.

\section{Introduction}

Cerebral palsy (CP) refers to a group of neurodevelopmental disorders characterized by permanent motor impairment, sometimes associated with comorbidities, such as seizures, intellectual disability, speech, visual and hearing difficulties. It is caused by lesions in the developing brain that occur before, during or in the first two years after birth. CP is the most common cause for disability in children $[1,2]$.

Different neuromotor types of $\mathrm{CP}$ are described, with the bilateral spastic subtype as the most frequent manifestation [3]. Spasticity is an important clinical aspect that affects motion patterns and muscular control. Furthermore, it is generally considered to be a crucial contributor to functional limitations, discomfort and gait abnormalities [4]. The supposed pathophysiology is an excessive afferent input onto intramedullary neurons without the expected inhibitory signals from the corticospinal tract, which is disrupted in case of $\mathrm{CP}$ associated cerebral damage $[5,6]$. The mechanism of selective dorsal rhizotomy (SDR) is based on this pathophysiology. This technique, mainly performed at the lumbar level, reduces muscular spasticity by eliminating the redundant incoming neurosensory signaling [7]. Previous studies reported that this intervention in combination with physiotherapy results in an increase in passive range of motion (ROM), along with positive impacts on the gait pattern and gross motor function $[8,9]$. SDR at a young

${ }^{\star}$ Correspondence to: Anja Van Campenhout, Department of Development and Regeneration, KU Leuven and Department of Orthopaedics, University Hospital Leuven, Herestraat 49, 3000 Leuven, Belgium, E-mail: anja. vancampenhout@uzleuven.be

Key words: cerebral palsy, dorsal rhizotomy, femoral derotation osteotomy, gait evaluation

Received: February 16, 2021; Accepted: February 23, 2021; Published: February 26,2021 

cases

age was found to limit the occurrence of secondary problems, such as deformities or contractures [10,11]. Strict selection criteria for SDR are essential. Although lacking an international consensus, most clinicians agree that a good candidate is a child with bilateral spastic $\mathrm{CP}$ with high spasticity in lower limb muscles, possessing enough selective motor control and strength [12].

Additionally to spasticity, children with bilateral spastic CP often present with bony malrotations of the lower limbs [13]. These osseous changes in the growing skeleton are mostly caused by muscular imbalances, partly resulting from spasticity. Due to the disparity of the abductor and adductor muscles of the hip, the physiological detorsion of the femoral anteversion is reduced or absent, resulting in an increased femoral neck anteversion $[14,15]$. This high anteversion leads to a reduction of the internal hip abduction moment arm, an increased anterior pelvic tilt and a compensatory internal rotation of the hip to restore abduction capacity [16-18]. During gait, this mechanism results in inward-pointed knees and feet, also referred to as 'intoeing gait'. Furthermore, high femoral anteversion is also part of the etiological mechanism of hip problems in less functional children and increases the risk of developing hip dysplasia, if left untreated $[19,20]$. The prevention and treatment of hip deformities is essential to improve gait and to avoid long-term complications. Femoral derotation osteotomy (FDO) is thought to be the best surgery to correct excessive femoral neck anteversion and internal hip rotation deformity [21]. Previous studies reported optimized postoperative transverse plane alignment and overall gait kinematic improvements [22]. The indication for FDO is based on clinical symptoms, such as toeing in or tripping, clinical exam and gait evaluation. Children with a clinical assessed increased femoral anteversion of more than $35^{\circ}$, an internal hip rotation of more than $60^{\circ}$ with an external hip rotation of less than $10^{\circ}$ when prone, presenting during gait with internal hip rotation of more than $15^{\circ}$ and/or an increased mean pelvic tilt typically are candidates for FDO $[12,23]$.

In most centers, SDR is performed at a young age, and is later often followed by an intervention to correct bony malrotations, if required. However, difficulties associated with a high femoral anteversion thereby often disturb rehabilitation after SDR. Further, it was demonstrated that the effect of SDR on gait was only significant in the mid- to long-term, once bony malrotations were also adjusted [12]. These results suggest that treatment should focus simultaneously on both spasticity and bony lever arms.

During every surgical intervention, there is a risk of complications and postoperative pain. Furthermore, intensive rehabilitation is required after SDR and after FDO, which may be difficult for a young child. Two separate interventions increase the burden of care on the family and lengthen the time of full recovery. Therefore, the specialized CP team of the University Hospital of Leuven has chosen to perform both interventions at the same moment. Their intention was to reduce the time of rehabilitation, while preserving similar outcomes. The aim of this paper is to document the results of the simultaneous combination of SDR and FDO. The improvement of gait, assessed by the change in the gait profile score (GPS) as primary outcome measure and complications of the combined procedure were documented. It was hypothesized that the gait improvements equalize these of a group of patients who underwent FDO prior to SDR and are better than patients who had SDR-only.

\section{Methods}

\section{Study design, participants and data collection}

In this study, we prospectively collected data from children with bilateral spastic cerebral palsy, who received simultaneous FDO and SDR between $9 / 2016$ and $2 / 2018$. These children were selected for this combined surgery based upon the current indications for SDR and FDO, which have been introduced before: presence of spasticity, adequate trunk control, sufficient muscle strength and selectivity, high femoral anteversion presenting with excessive internally rotated hips and/or an increased pelvic tilt during gait. As part of the preoperative evaluation, minimum six months before a SDR procedure, a multilevel infiltration with botulinum toxin in the spastic lower limb muscles was performed to assess strength and motor function after spasticity reduction, which was investigated by means of a three dimensional gait analysis (3DGA) pre-and post-infiltration. The primary outcome parameter GPS and other selected gait features were extracted from the preoperative and one and two years postoperative 3DGA data. Medical history, complications and the course of their hospitalization and rehabilitation were recorded. All data were anonymized a priori. Further, the data from two reference groups were used: patients who only received SDR and a patient group who underwent SDR after FDO in an earlier stage. These retrospective control data were obtained from a previous study in our center on the outcome of SDR and/or FDO [12].

The parents and children gave their informed consent for the use of their children's data for scientific purposes. Ethical approval for this study was acquired from the Medical Ethical Committee of the University Hospital of Leuven, Belgium (MP014080).

\section{Surgical procedures}

Surgery started with the SDR procedure followed by FDO. General anesthesia without neuromuscular blocking agents was used. SDR was performed according to the technique described by Peacock, et al. [24], with some modifications. In short, the patient was positioned in prone Trendelenburg position, and L1-L5 laminotomies were performed with a craniotome, and left hinging on the interspinous ligament T12-L1. Under microscopic magnification, a durotomy was performed and the sensible roots were identified anatomically and by means of electromyography (EMG). Next, each root was divided into 5-30 rootlets, and electrically stimulated one by one, under EMG and clinical (palpation by the physiotherapist) monitoring. Only rootlets in which electrical stimulation provoked an abnormal response and/or clinical contraction and without responses in the $\mathrm{mm}$. sphincter ani, $\mathrm{mm}$. glutei, $\mathrm{m}$. vastus lateralis and $\mathrm{m}$. soleus, were severed with microscissors [25]. Typically, the transection rate was $20-30 \%$. The dura was then closed primarily and the laminae were sutured back in place. Subsequently, in the same prone position, the orthopaedic FDO procedure was done: a transverse proximal femoral derotation osteotomy was performed. The amount of derotation was based on kinematic gait analysis and peroperative physical examination measurements. The osteotomy was fixated with a blade plate (Orthopaediatrics ${ }^{\circledR}$ ). In case of excessive external tibial torsion of more than 20 degrees, a tibia derotation osteotomy followed. No soft tissue procedures were done.

\section{Gait analysis}

Maximum two months before the combined procedure and one and two years postoperatively, a gait analysis took place at the Clinical Motion Analysis Laboratory of the University Hospital of Leuven. The standard 3DGA included recording of kinematic and kinetic data and EMG signals from the most important muscles in the lower limbs. 

cases

Hereto, a 10 to 12 optoelectronic camera system, operating at 100 $\mathrm{Hz}$ (Vicon, Oxford, UK) and two force plates, recording the ground reaction forces $(1,000 \mathrm{~Hz})$ (AMTI, Watertown, USA) were used, and EMG was measured with a telemetric 16 channel surface EMG system (Zero wire, Cometa, Milan, Italy). For the current study, only kinematic data of the 3DGA were used. Retroreflective markers located at specific anatomic landmarks of the subjects' lower limbs were placed by trained therapists, according to the lower limb Vicon PluginGait marker configuration (VICON, Oxford Metrics, Oxford, UK). Children were instructed to walk barefoot along a 10 meter walkway at their usual selfselected comfortable walking speed. A trial was considered of acceptable quality when there was clear indicator visibility. Vicon Nexus software (Oxford Metrics, Oxford, UK) calculated the lower limb kinematics of the identified gait cycles by indicating the events of initial contact and toe off. Gait parameters were extracted from the continuous kinematic waveforms using custom made Matlab ${ }^{\circledR}$ software (The Mathworks Inc., Natick, M.A., 2015). A clinical examination preceded the 3DGA to refine the personalization of the muscle parameters, including measurements of the passive range of motion (pROM) in degrees and clinical assessment of spasticity, strength and selectivity.

\section{Data processing}

The gait profile score (GPS) was used as primary outcome measure to quantify the level of pathological gait for each subject individually $[26,27]$. The GPS is the root mean square (RMS) average of the global variable scores (GVS) variables. The GVS is defined for the pelvis, hip, knee, ankle and foot, and, when relevant, separately in the sagittal, frontal and transverse plane, as the RMS difference between a specific time normalized gait variable and the mean data from people with no gait pathology calculated across the gait cycle. A higher GPS indicates a more pathological gait in comparison to a lower GPS. To evaluate the progress after the intervention, a difference score was made by subtracting the preoperative GPS from the postoperative GPS, named as dGPS. Negative values indicate improvement, positive values indicate deterioration. The minimal clinically important difference (MCID) of $1.6^{\circ}$ was used to assess the significance of the dGPS [27]. Moreover, other specific gait features extracted from the kinematic waveforms of the pelvis, hip, knee and foot in different anatomical planes were defined for each gait analysis session. The results of the legs were presented separately as both surgical procedures were tuned individually.

This outcome was compared with the two control groups. Because of the nature of this pilot study with a small number of patients, only descriptive analyses were done.

To classify and describe the patients function and mobility, the gross motor function classification scale (GMFCS) [28], the functional mobility scale (FMS) [29] and the Gillette functional assessment questionnaire (Gillette FAQ) [30] were used.

Furthermore, adverse events of the combined procedure were classified using the modified Clavien-Dindo (MCD) system [31,32], graded from 1 to 5 .

\section{Results}

Three children with bilateral spastic CP had a simultaneous FDO and SDR procedure between 9/2016 and 2/2018 and all three had the necessary preoperative-, short- and medium-term postoperative gait evaluations. Patient characteristics are presented in Table 1.

\section{Intervention and adverse events}

The intervention was performed between the ages of 8 and 12 years, as presented in Table 2. The percentage of each posterior rootlet transected was very selective, with percentages ranging from $14.6 \%$ to $34.4 \%$ per side. Besides the bilateral femoral derotation, patient 3 had also unilateral tibial derotation. No soft tissue surgery was done prior to, at the time of the combined surgery or in the two year follow-up.

All three patients had a substantial postoperative drop in hemoglobin for which a blood transfusion was necessary, which is an adverse event classified as a Modified Clavien-Dindo (MCD) grade 2 (Table 2). Further, the following adverse events were recorded as single events: constipation for which an enema was needed (MCD II) and episode of postoperative spasms, nausea, postoperative fever or hypophosphatemia (all MCD I).

Postoperatively, all patients stayed in the hospital for 4 or 5 days, followed by a rehabilitation period of 12 to 16 weeks in a specialized center, where the children had 2 hours of physiotherapy per day, supervised positioning and on-site teaching. During the rehabilitation period, all patients first started walking with a walking aid (Kayewalker). Only after acquiring enough strength and a stable gait, which was usually only after four to six months, patients were allowed to walk independently. Assistive devices (ankle foot orthoses, knee extension braces and standing frames) were used extensively.

The GMFCS and the Gillette FAQ stayed stable postoperative. FMS values improved in all 3 children at 2-year follow-up.

\section{Gait analysis}

The gait analysis took place preoperatively (2-42 days), one year (11.11 years) and two years (2.05-2.19 years) post-surgery. Only patient 3 (GMFCS 3) walked with the help of a Kaye-walker in the pre- and postoperative gait analyses. The GPS and specific gait parameters are shown in Figure 1, Table 3. At baseline, patient 3 had the highest GPS, matching with the GMFCS III. All GPS values improved compared

Table 1. Study sample characteristics

\begin{tabular}{|c|c|c|c|}
\hline & Case 1 & Case 2 & Case 3 \\
\hline Gender & Boy & Girl & Boy \\
\hline PMA weeks & 30 & 29 & 27 \\
\hline Birthweight kilograms & 1.670 & 1.510 & 1.250 \\
\hline GMFCS & II & II & III \\
\hline Gillette FAQ pre \& post 1y/2y & 9 & 8 & 6 \\
\hline Preoperative FMS & $5 / 4 / 1$ & $5 / 5 / 2$ & $4 / 2 / 1$ \\
\hline 1Y post FMS & $5 / 5 / 1$ & $6 / 6 / 5$ & $2 / 2 / 1$ \\
\hline 2Y post FMS & $5 / 5 / 1$ & $6 / 5 / 1$ & $5 / 2 / 1$ \\
\hline Number BTX infiltrations & 5 & 4 & 5 \\
\hline
\end{tabular}

PMA: Postmenstrual age; GMFCS: Gross motor function classification scale; Gillette FAQ: Functional assessment questionnaire; FMS: Functional mobility scale; Y: Year; BTX: Botulinum toxin.

Table 2. Perioperative data

\begin{tabular}{|c|c|c|c|}
\hline & Case 1 & Case 2 & Case 3 \\
\hline Age of intervention years & 12 & 9 & 8 \\
\hline $\begin{array}{c}\text { Weight at the moment of } \\
\text { intervention kilograms }\end{array}$ & 26.7 & 34.4 & 19.7 \\
\hline $\begin{array}{c}\text { Percentage transected sensory } \\
\text { rootlets right/left \% }\end{array}$ & $23.5 / 27$ & $14.6 / 30.4$ & $19.3 / 29.7$ \\
\hline Maximum Hb fall g/dl & 4.9 & 5.3 & 6.9 \\
\hline Lowest Hb g/dl & 7.7 & 7.3 & 7.1 \\
\hline Length of hospitalization days & 4 & 5 & 5 \\
\hline $\begin{array}{c}\text { Intensive rehabilitation period } \\
\text { weeks }\end{array}$ & 13 & 12 & 16 \\
\hline
\end{tabular}

FDO: Femoral derotation osteotomy; SDR: Selective dorsal rhizotomy; TDO: Tibial derotation osteotomy; Hb: Hemoglobin. 

cases

to preoperative, mostly with changes larger than the MCID value of $1.6^{\circ}$. Gait parameters showed a large decrease in anterior pelvic tilt and an improvement in hip extension in both GMFCS II patients. In the GMFCS III boy, anterior pelvic tilt remained high but he achieved a good increase in hip extension during stance. Postoperatively, there was a good correction of hip rotation in five out of six limbs; only one leg still showed a mild excess of internal rotation. When walking barefoot, only patient 3 had a good correction of minimum knee extension in stance phase. Patient 2 had an improvement on one side, while patient 1 still had a high knee flexion. The knee angle at initial contact decreased, except for the right knee of patient 2, which remained unchanged two years postoperatively. All three patients had an increase in total knee ROM, with an improvement of knee flexion in swing, which was a problem before surgery. Furthermore, a good ankle dorsiflexion was present in all three cases. Postoperatively, all three patients had a mild physiologic toeing out gait, with a correction of intoeing gait where this was present preoperatively.

\section{The control group}

The results of the three cases with the combined SDR-FDO surgery were compared with a group of fourteen children with FDO prior to SDR (about one year apart) and fifteen children with SDR-only, regarding gait outcome one year after the last surgery [12]. Clinical data of the three patients in comparison with both control groups (Table 4) show a higher number of GMFCS I and II patients in the control groups. GPS and specific gait features preoperatively and one year postoperatively are presented in Table 5 . An improvement in gait is observed in the three groups, represented by the negative dGPS scores (Figure 2). Yet, only the simultaneous SDR-FDO and the group with FDO prior to SDR clearly exceeded the MCID for GPS $\left(1.6^{\circ}\right)$. Due to the FDO intervention, the largest changes in mean internal rotation of the hip were seen in the three SDR-FDO cases and the FDO prior to SDR group. A larger improvement in mean pelvic tilt $\left(5.08^{\circ}\right)$ and minimum hip extension $\left(7.68^{\circ}\right)$ was found in the SDR-FDO children,

Table 3. Gait analysis: GPS and specific gait parameters

\begin{tabular}{|c|c|c|c|c|c|c|c|c|c|}
\hline & Patient 1 & & & Patient 2 & & & Patient 3 & & \\
\hline & Preop & $1 \mathrm{y}$ postop & $2 y$ postop & Preop & $1 \mathrm{y}$ postop & $2 y$ postop & Preop & $1 \mathrm{y}$ postop & $2 y$ postop \\
\hline GPS $\left(^{\circ}\right) \mathrm{L}$ & 12.90 & 7.66 & 9.17 & 13.03 & 7.95 & 7.62 & 16.02 & 10.98 & 11.17 \\
\hline GPS $\left(^{\circ}\right) \mathrm{R}$ & 10.32 & 6.48 & 8.88 & 13.26 & 10.13 & 10.82 & 14.63 & 12.74 & 10.81 \\
\hline \multicolumn{10}{|l|}{ Pelvis } \\
\hline Mean pelvic tilt $\left(^{\circ}\right) \mathrm{L}$ & 19.42 & 13.90 & 11.70 & 25.08 & 18.26 & 10.21 & 26.85 & 24.10 & 24.89 \\
\hline Mean pelvic tilt $\left(^{\circ}\right) \mathrm{R}$ & 19.58 & 14.03 & 11.71 & 24.78 & 17.97 & 10.32 & 27.71 & 24.65 & 24.41 \\
\hline Pelvic ROM $\left(^{\circ}\right) \mathrm{L}$ & 15.06 & 9.52 & 7.11 & 9.75 & 5.82 & 5.50 & 8.31 & 5.20 & 6.94 \\
\hline Pelvic ROM $\left(^{\circ}\right) \mathrm{R}$ & 13.74 & 8.64 & 7.28 & 10.29 & 6.65 & 5.30 & 8.53 & 6.15 & 7.35 \\
\hline \multicolumn{10}{|l|}{ Hip } \\
\hline Min hip extension in stance $\left(^{\circ}\right) \mathrm{L}$ & 12.32 & 4.25 & 5.08 & 5.81 & 1.18 & -3.89 & 24.45 & 10.19 & 4.06 \\
\hline Min hip extension in stance $\left(^{\circ}\right) \mathrm{R}$ & 4.95 & -6.29 & -4.12 & 3.66 & 0.20 & -2.68 & 16.21 & 11.80 & 9.57 \\
\hline ROM hip in sagittal plane $\left(^{\circ}\right) \mathrm{L}$ & 38.85 & 38.46 & 38.20 & 55.15 & 50.28 & 50.81 & 42.85 & 41.54 & 52.24 \\
\hline ROM hip in sagittal plane $\left(^{\circ}\right) \mathrm{R}$ & 44.94 & 48.24 & 48.49 & 57.43 & 55.42 & 53.72 & 45.46 & 46.83 & 50.82 \\
\hline Mean angle hip in transverse plane $\left(^{\circ}\right) \mathrm{L}$ & 17.79 & 3.23 & 2.71 & 9.11 & 1.63 & 5.84 & 22.00 & 10.99 & 13.11 \\
\hline Mean angle hip in transverse plane $\left(^{\circ}\right) \mathrm{R}$ & -2.55 & -0.69 & 4.71 & 10.18 & -2.25 & -4.19 & 7.36 & -11.05 & -1.66 \\
\hline \multicolumn{10}{|l|}{ Knee } \\
\hline Min knee extension in stance $\left(^{\circ}\right) \mathrm{L}$ & 25.34 & 21.62 & 30.43 & 23.18 & 12.56 & 14.13 & 26.42 & 6.12 & 6.95 \\
\hline Min knee extension in stance $\left(^{\circ}\right) \mathrm{R}$ & 25.31 & 15.94 & 23.94 & 17.35 & 12.30 & 18.70 & 26.96 & 5.87 & 6.90 \\
\hline Knee angle at initial contact $\left(^{\circ}\right) \mathrm{L}$ & 35.91 & 27.74 & 31.40 & 39.02 & 21.22 & 29.12 & 37.57 & 16.58 & 22.51 \\
\hline Knee angle at initial contact $\left(^{\circ}\right) \mathrm{R}$ & 29.18 & 20.18 & 26.47 & 38.37 & 29.20 & 38.34 & 44.92 & 17.25 & 23.73 \\
\hline Max knee flexion in swing $\left(^{\circ}\right) \mathrm{L}$ & 64.57 & 72.98 & 72.45 & 63.50 & 70.86 & 69.63 & 73.96 & 63.33 & 69.69 \\
\hline Max knee flexion in swing $\left(^{\circ}\right) \mathrm{R}$ & 62.10 & 63.81 & 68.32 & 67.83 & 75.51 & 80.51 & 80.89 & 73.49 & 76.38 \\
\hline ROM knee in sagittal plane $\left(^{\circ}\right) \mathrm{L}$ & 39.23 & 51.36 & 42.02 & 40.32 & 58.30 & 55.50 & 47.54 & 57.21 & 62.74 \\
\hline ROM knee in sagittal plane $\left(^{\circ}\right) \mathrm{R}$ & 36.78 & 47.87 & 44.39 & 50.48 & 63.21 & 61.82 & 53.93 & 67.62 & 69.48 \\
\hline \multicolumn{10}{|l|}{ Ankle } \\
\hline Max ankle dorsiflexion in stance $\left(^{\circ}\right) \mathrm{L}$ & 9.82 & 13.52 & 16.60 & 20.77 & 21.98 & 22.57 & 15.48 & 18.38 & 16.70 \\
\hline Max ankle dorsiflexion in stance $\left(^{\circ}\right) \mathrm{R}$ & 17.52 & 18.23 & 21.80 & 22.81 & 22.30 & 27.46 & 22.79 & 17.49 & 19.73 \\
\hline Mean angle of foot in sagittal plane in swing $\left(^{\circ}\right) \mathrm{L}$ & -12.41 & -3.65 & -4.21 & 0.33 & 7.98 & 5.57 & 5.79 & 7.41 & 2.91 \\
\hline Mean angle of foot in sagittal plane in swing $\left(^{\circ}\right) \mathrm{R}$ & 1.11 & 2.71 & 11.28 & 3.23 & 5.31 & 9.37 & 7.81 & -0.05 & 1.40 \\
\hline \multicolumn{10}{|l|}{ Foot } \\
\hline Mean angle of foot in transverse plane in stance $\left(^{\circ}\right) \mathrm{L}$ & 7.81 & -10.70 & -13.71 & 7.84 & -4.42 & -8.21 & 8.20 & -10.29 & -14.27 \\
\hline Mean angle of foot in transverse plane in stance $\left(^{\circ}\right) \mathrm{R}$ & -3.70 & -15.44 & -17.14 & 11.07 & -12.38 & -12.43 & -0.22 & -13.88 & -9.44 \\
\hline
\end{tabular}

GPS: Gait profile score; ${ }^{\circ}$ : Degrees; Y: Year; Preop: Preoperatively; Postop: Postoperatively; L: Left side; R: Right side; Min: Minimum; Max: Maximum; ROM: Range of motion.

Table 4. Age, sex and GMFCS of the 3 cases, the FDO prior to SDR group and the SDR-only group [12]

\begin{tabular}{|c|c|c|c|}
\hline & FDO+SDR \\
$(\mathbf{N = 3 )}$ & $\begin{array}{c}\text { SDO prior to SDR } \\
(\mathbf{N}=\mathbf{1 4})\end{array}$ \\
\hline Average age (range) years & $9.5(7.3-12.4)$ & $10.7(7.8-13.6)$ \\
\hline Male/ female sex \% & $66 / 33$ & $43 / 57$ \\
\hline GMFCS I/II/III \% & $0 / 66 / 33$ & $43 / 57 / 0$ \\
\hline
\end{tabular}

FDO: Femoral derotation osteotomy; SDR: Selective dorsal rhizotomy; N: Number of patients; GMFCS: Gross motor function classification scale. 
Schreurs H (2021) Simultaneous femoral derotation osteotomy and selective dorsal rhizotomy in children with spastic cerebral palsy: A prospective follow-up of 3 cases

Table 5. Comparison of the three cases (six legs) with the FDO prior to SDR group and the SDR-only group.

\begin{tabular}{|c|c|c|c|c|c|c|}
\hline & \multicolumn{2}{|c|}{$\begin{array}{l}\text { Mean (range) SDR-FDO } \\
(\mathbf{N}=6)\end{array}$} & \multicolumn{2}{|c|}{$\begin{array}{l}\text { Mean (range) FDO prior to SDR } \\
(\mathbf{N}=\mathbf{2 8})\end{array}$} & \multicolumn{2}{|c|}{$\begin{array}{c}\text { Mean (range) SDR-only } \\
(\mathbf{N}=\mathbf{3 0})\end{array}$} \\
\hline & preop & 1y postop & preop & 1y postop & preop & 1y postop \\
\hline $\operatorname{GPS}\left({ }^{\circ}\right)$ & $\begin{array}{c}13.36 \\
(10.32-16.02)\end{array}$ & $\begin{array}{c}9.32 \\
(6.48-12.74)\end{array}$ & $\begin{array}{c}12.67 \\
(8.48-19.84)\end{array}$ & $\begin{array}{c}8.85 \\
(4.35-16.04)\end{array}$ & $\begin{array}{c}10.41 \\
(6.56-17.82)\end{array}$ & $\begin{array}{c}9.70 \\
(6.66-12.99)\end{array}$ \\
\hline dGPS $\left({ }^{\circ}\right)$ & \multicolumn{2}{|c|}{$-4.04(-5.24-1.90)$} & \multicolumn{2}{|c|}{$-3.82(-11.14-3.11)$} & \multicolumn{2}{|c|}{$-0.71(-6.87-4.37)$} \\
\hline $\begin{array}{l}\text { Mean internal } \\
\text { rotation of the hip }\left(^{\circ}\right)\end{array}$ & $\begin{array}{c}10.65 \\
(-2.55-22.00)\end{array}$ & $\begin{array}{c}0.31 \\
(-11.05-10.99)\end{array}$ & $\begin{array}{c}14.63 \\
(4.10-27.60)\end{array}$ & $\begin{array}{c}4.13 \\
(-9.17-25.50)\end{array}$ & $\begin{array}{c}4.94 \\
(-23.03-26.61)\end{array}$ & $\begin{array}{c}-0.64 \\
(-14.16-19.49)\end{array}$ \\
\hline Mean pelvic tilt $\left(^{\circ}\right)$ & $\begin{array}{c}23.90 \\
(19.42-27.71)\end{array}$ & $\begin{array}{c}18.82 \\
(13.90-24.65)\end{array}$ & $\begin{array}{c}18.57 \\
(-0.26-35.70)\end{array}$ & $\begin{array}{c}16.78 \\
(4.47-32.57)\end{array}$ & $\begin{array}{c}19.53 \\
(-5.17-40.77)\end{array}$ & $\begin{array}{c}19.73 \\
(0.97-30.56)\end{array}$ \\
\hline $\begin{array}{l}\text { Minimum hip } \\
\text { extension }\left({ }^{\circ}\right)\end{array}$ & $\begin{array}{c}11.24 \\
(3.66-24.45)\end{array}$ & $\begin{array}{c}3.56 \\
(-6.29-11.80)\end{array}$ & $\begin{array}{c}-1.76 \\
(-13.82-11.13)\end{array}$ & $\begin{array}{c}-3.81 \\
(-18.84-9.23)\end{array}$ & $\begin{array}{c}-1.55 \\
(-19.74-20.98)\end{array}$ & $\begin{array}{c}0.71 \\
(-18.97-9.34)\end{array}$ \\
\hline $\begin{array}{l}\text { Knee angle at initial } \\
\text { contact }\left(^{\circ}\right)\end{array}$ & $\begin{array}{c}37.50 \\
(29.18-44.92)\end{array}$ & $\begin{array}{c}22.03 \\
(16.58-29.20)\end{array}$ & $\begin{array}{c}32.07 \\
(15.00-63.91)\end{array}$ & $\begin{array}{c}18.04 \\
(5.31-32.82)\end{array}$ & $\begin{array}{c}29.36 \\
(7.63-39.96)\end{array}$ & $\begin{array}{c}17.37 \\
(2.12-27.31)\end{array}$ \\
\hline $\begin{array}{c}\text { Maximum knee } \\
\text { extension in stance }\left(^{\circ}\right)\end{array}$ & $\begin{array}{c}42.31 \\
(36.11-49.00)\end{array}$ & $\begin{array}{c}28.82 \\
(17.74-38.55)\end{array}$ & $\begin{array}{c}11.85 \\
(-14.98-56.48)\end{array}$ & $\begin{array}{c}4.6 \\
(-9.73-20.14)\end{array}$ & $\begin{array}{c}6.23 \\
(-10.03-24.41)\end{array}$ & $\begin{array}{c}4.30 \\
(-6.65-13.76)\end{array}$ \\
\hline
\end{tabular}

GPS: Gait profile score; Range: Minimum - Maximum; d: Difference score (postoperative value minus preoperative value); FDO: Femoral derotation osteotomy; SDR: Selective dorsal rhizotomy; Preop: Preoperatively; Y: Year; Postop: Postoperatively; N: Number of limbs.

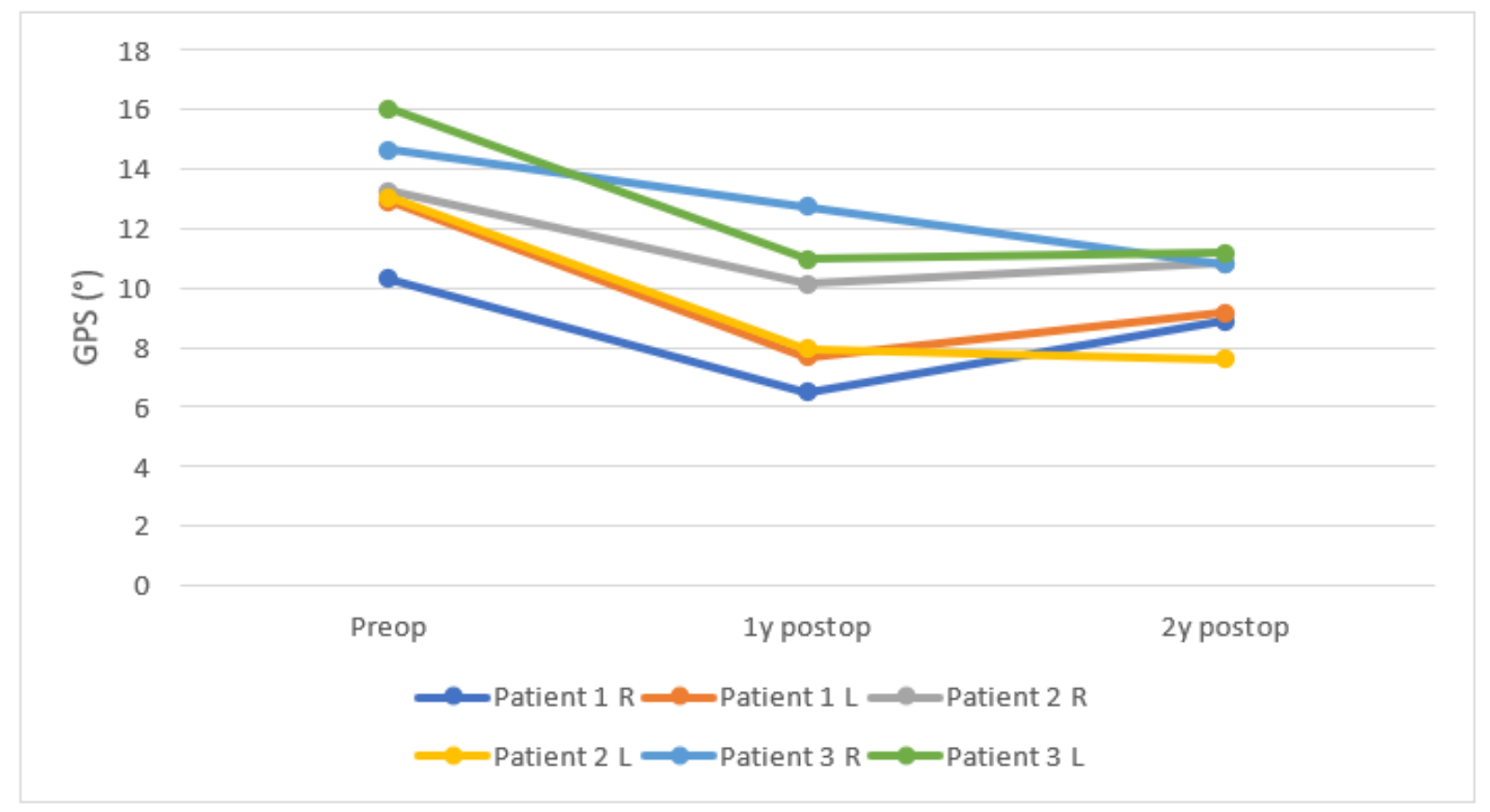

Figure 1. The preoperative, 1- and 2-year postoperative GPS of the six legs of the SDR-FDO patients

GPS: Gait profile score; ${ }^{\circ}$ : Degrees; SDR: Selective dorsal rhizotomy; FDO: Femoral derotation osteotomy; R: Right leg; L: Left leg; Y: Year; Preop: Preoperatively; Postop: Postoperatively.

but with a large range in improvement due to the small sample size. Values of knee kinematics improved in all three groups.

\section{Discussion}

This case series is the first description of the combined SDR and FDO procedure. These procedures were combined to offer both a spasticity treatment and a correction of bony lever arms in carefully selected children with bilateral spastic cerebral palsy. The outcome on gait with a follow-up of two years and the postoperative course with its adverse events were described. Furthermore, the GPS and specific gait features were compared with previously published data of children who received SDR-only or who underwent SDR after FDO, who could be used as control groups.
Overall gait, expressed as GPS, significantly improved one year postoperatively and remained stable in the following year. Improved gait has previously also been reported after isolated SDR [8,33-37], isolated FDO interventions [22,38-40] and after performing both procedures at different time-episodes [12]. The dGPS values of the three patients of the current study and the FDO prior to SDR group clearly exceeded the MCID [27], in contrast to the SDR-only group. The positive results in the simultaneous SDR-FDO group are presumably multifactorial: the combination of spasticity reduction and correction of bony malrotations in patients that were selected using strict guidelines regarding strength and selectivity, and an intensive rehabilitation period with personally customized assistive devices and physiotherapy. The largest changes in GPS were observed in the sagittal plane, due to the SDR procedure, and the transverse plane, as a result of the FDO intervention. 

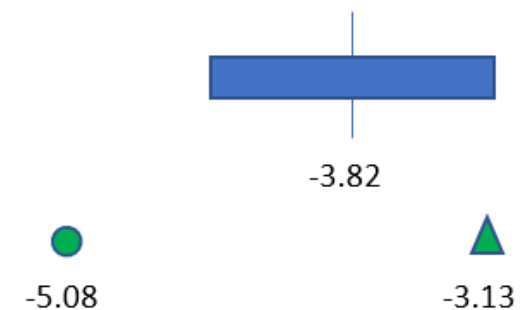

$-5.24$

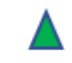

$-3.13$

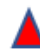

$-3.84$

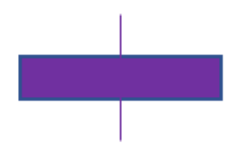

$-0.71$

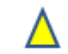

$-1.89$

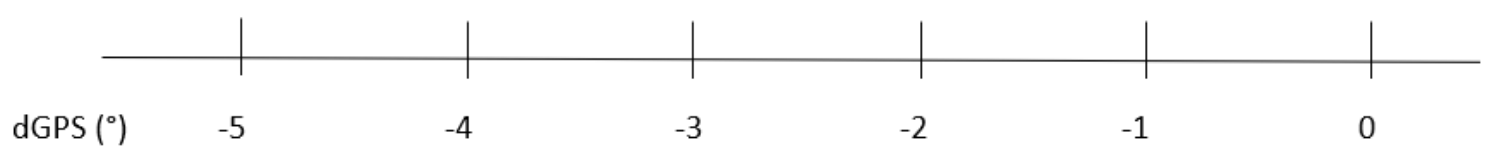

\begin{tabular}{ll|ll}
\hline & Patient 1 left leg & \multicolumn{1}{c}{ Patient 1 right leg } \\
\hline \multicolumn{1}{|c|}{ Patient 2 left leg } & \multicolumn{1}{|c}{ Patient 2 right leg } \\
\hline$\bigcirc$ & Patient 3 left leg & \multicolumn{1}{|c|}{ Patient 3 right leg } \\
\hline & FDO prior to SDR & SDR only \\
\hline
\end{tabular}

Figure 2. The dGPS of the reference groups and the three SDR-FDO patients

GPS: Gait profile score; ${ }^{\circ}$ : Degrees; d: Difference score (postoperative value minus preoperative value); SDR: Selective dorsal rhizotomy; FDO: Femoral derotation osteotomy

FDO led to less internally rotated hips with an associated improvement and more physiological position of the foot progression angle. Various studies yielded the same effects of this procedure, even at a longer period of follow-up [22,38-40]. Furthermore, some studies $[22,41]$ have described a better hip extension after FDO, similar to our data. Literature has shown conflicting results on the effect of SDR-only for the maximum hip extension in stance. An improvement $[8,33,42]$, a deterioration $[12,37]$ or no significant effect $[34,35]$ on hip extension have been found in previous studies. The current results support the beneficial effects of the associated FDO on the hip kinematics.

A normal pelvic tilt is important in preserving a functional, painless gait as adult [43]. A significant decrease in the preoperative elevated anterior pelvic tilt was observed one and two years postoperatively, especially in the two patients with a GMFCS II. These gait findings were not in agreement with those of previously published work after SDR-only, which showed no significant changes in kinematics of pelvis [37] or even a deteriorated (increased) anterior pelvic tilt [34,36]. After FDO-only, some studies described no significant changes [41], while others reported a decline in pelvic tilt at the long term [40]. The study by Van Campenhout, et al. [12] demonstrated that pelvic tilt deteriorated after SDR but remained stable when FDO was received before SDR. These results highlight the benefits of the combination intervention SDR-FDO in the context of pelvic tilt.

Gait analyses in the three cases showed an inconsistent effect on knee kinematics. The results of patient 3 , who was classified as level GMFCS III, showed a significant improvement in knee extension at initial contact and in stance. In both patients that were classified as level GMFCS II, an improved knee flexion during swing phase was seen, in accordance with studies after SDR-only $[36,37]$. Furthermore, similar to the current results, there is no unanimity in literature about the effect of SDR on knee extension in stance. Some studies have demonstrated an improvement in knee extension in stance $[33,34,42]$. Other studies $[36,37]$ showed no significant effect during midstance but a significant improvement in knee extension at initial contact, similar to patient 1 of the current study. An increased range of motion of the knee was found for all three cases, which was also repeatedly mentioned in SDR-only studies $[34,37]$. More research on the combined SDR-FDO is needed to study the long-term effect on knee kinematics, including the effect for different GMFCS groups.

3DGA was used to estimate muscle lengths during gait, to guide the need for surgical muscle lengthening procedures. It is important to notice that no muscle lengthening surgery were done when performing the combined SDR-FDO procedure, nor within the follow-up period. A good spasticity treatment at young age using medication and botulinum toxin treatment when needed, followed by SDR, and regular physiotherapy and the use of orthoses, could prevent muscle shortening and the need for soft tissue surgery.

The overall lower limb function of the children was scored using the FMS and the Gillettes FAQ. During the follow-up period, the Gillettes FAQ remained unchanged, while the FMS improved slightly, but inconsistently. Besides lower limb function, this can probably be explained by factors such as anxiety or the preference of using a wheelchair to keep up with the speed of peers, for example as an adolescent in high school.

Adverse events are common after both SDR and FDO procedure, with dys- or hyperesthesia among the most frequent reported symptoms after SDR-only [44-46]. In the current study, mostly mild 

cases

complications (MCD I and II) were reported and no sensory deficits were documented during the follow-up period. All three patients had large hemoglobin fall and needed a blood transfusion. Avoiding blood loss is important. From our experience with the combined procedure, the importance of correct installation became clear. After the SDR procedure, the patient stayed in prone position. Yet, it became clear that some of the cushions used by the neurosurgeons to install the child in optimal position to operate on the spine while preventing pressure problems, can be removed when operating on the lower limbs in a more stable position. This position could make surgery faster and could facilitate fixation, thereby limiting blood loss during the orthopedic procedure in subsequent patients. The prolonged time of surgery remains a challenge. Yet, by combining both needed surgeries, only one anesthesia and more importantly one period of hospitalization and one period of rehabilitation, one period away from house, school, family and friends is needed. The combined SDR-FDO approach may reduce the psychological burden of the intervention. Every surgery can be a difficult experience for children to deal with. Previous studies have proven that approximately $50 \%-75 \%$ of children suffer from anxiety during the perioperative time course [47]. Subsequent interventions would increase the risk of maladaptive behavior $[48,49]$. The possibility of combining both surgeries and hence a reduction in hospital stays and rehabilitation periods, can potentially contribute to a better quality of life and participation.

The current study is very limited in his number of subjects. This small sample size makes it difficult to compare the data with the values of the reference group. Also, longer follow-up with more extensive report on function, participation and quality of life is needed. With this preliminary report on the first three patients that had the combined treatment of spasticity by SDR and bony lever arm problems by bilateral FDO, it was documented that this is a plausible and safe procedure with good outcome on gait.

\section{Conclusion}

We conclude that combining SDR and bilateral FDO surgeries at the same moment in children with spastic bilateral cerebral palsy who need both spasticity reduction and correction of bony malrotations is a safe and successful procedure. No serious adverse events were recorded. Overall gait and specific gait parameters improved more than after an SDR-only. Due to the reduced number of hospital admissions, a reduced psychological burden for the patients and their relatives can be expected. Further research on a larger sample and a longer follow-up time is needed.

\section{Conflict of interest}

We declare that we have no conflict of interest.

\section{Financial disclosure} article.

No funding has been received to support the development of this

\section{References}

1. Narayanan UG (2012) Management of children with ambulatory cerebral palsy: an evidence-based review. J Pediatr Orthop 32: S172-S181. [Crossref]

2. Gulati S, Sondhi V (2018) Cerebral palsy: An overview. Indian J Pediatr 85: 10061016. [Crossref]

3. Hagberg B, Hagberg G, Beckung E, Uvebrant P (2001) Changing panorama of cerebral palsy in Sweden. VIII. Prevalence and origin in the birth year period 1991-94. Acto Paediatr 90: 271-277. [Crossref]
4. Bar-On L, Molenaers G, Aertbeliën E, Van Campenhout A, Feys H, et al. (2015) Spasticity and its contribution to hypertonia in cerebral palsy. Biomed Res Int 2015 317047. [Crossref]

5. Johnston MV (2009) Plasticity in the developing brain: implications for rehabilitation. Dev Disabil Res Rev 15: 94-101. [Crossref]

6. Eyre JA (2007) Corticospinal tract development and its plasticity after perinatal injury Neurosci Biobehav Rev 31: 1136-1149. [Crossref]

7. Bakir MS, Gruschke F, Taylor WR, Haberl EJ, Sharankou I, et al. (2013) Temporal bu not spatial variability during gait is reduced after selective dorsal rhizotomy in children with cerebral palsy. PLoS One 8: e69500.

8. Abel MF, Damiano DL, Gilgannon M, Carmines D, Kang HG, et al. (2005) Biomechanical changes in gait following selective dorsal rhizotomy. J Neurosurg 102 157-162. [Crossref]

9. McLaughlin J, Bjornson K, Temkin N, Steinbok P, Wright V, et al. (2002) Selective dorsal rhizotomy: meta-analysis of three randomized controlled trials. Dev Med Child Neurol 44: 17-25. [Crossref]

10. O’Brien DF, Park TS, Puglisi JA, Collins DR, Leuthardt EC, et al. (2005) Orthopedic surgery after selective dorsal rhizotomy for spastic diplegia in relation to ambulatory status and age. J Neurosurg 103: 5-9. [Crossref]

11. MacWilliams BA, Johnson BA, Shuckra AL, D'Astous JL (2011) Functional decline in children undergoing selective dorsal rhizotomy after age 10. Dev Med Child Neurol 53: 717-723. [Crossref]

12. Van Campenhout A, Huenaerts C, Poulussen L, Prinsen SD, Desloovere K (2019) Role of femoral derotation on gait after selective dorsal rhizotomy in children with spastic cerebral palsy. Dev Med Child Neurol 61: 1196-1201. [Crossref]

13. Rethlefsen SA, Kay RM (2013) Transverse plane gait problems in children with cerebral palsy. J Pediatr Orthop 33: 422-430. [Crossref]

14. Metaxiotis D, Accles W, Siebel A, Doederlein L (2000) Hip deformities in walking patients with cerebral palsy. Gait Posture 11: 86-91. [Crossref]

15. Robin J, Graham HK, Selber P, Dobson F, Smith K, et al. (2008) Proximal femoral geometry in cerebral palsy: a population-based cross-sectional study. J Bone Joint Surg $\operatorname{Br}$ 90: 1372-1379. [Crossref]

16. Bruderer-Hofstetter M, Fenner V, Payne E, Zdenek K, Klima H, et al. (2015) Gait deviations and compensations in pediatric patients with increased femoral torsion. $J$ Orthop Res 33: 155-162. [Crossref]

17. Akalan NE, Temelli Y, Kuchimov S (2013) Discrimination of abnormal gait parameters due to increased femoral anteversion from other effects in cerebral palsy. Hip Int 23: 492-499. [Crossref]

18. Arnold AS, Komattu AV, Delp SL (1997) Internal rotation gait: a compensatory mechanism to restore abduction capacity decreased by bone deformity. Dev Med Child Neurol 39: 40-44. [Crossref]

19. Canavese F, Emara K, Sembrano JN, Bialik V, Aiona MD, et al. (2010) Varus derotation osteotomy for the treatment of hip subluxation and dislocation in GMFCS level III to $\mathrm{V}$ patients with unilateral hip involvement. Follow-up at skeletal maturity. J Pediatr Orthop 30: 357-364. [Crossref]

20. Soo B, Howard JJ, Boyd RN, Reid SM, Lanigan A, et al. (2006) Hip displacement in cerebral palsy. J Bone Joint Surg Am 88: 121-129. [Crossref]

21. Cobeljic G, Djoric I, Bajin Z, Despot B (2006) Femoral derotation osteotomy in cerebral palsy: precise determination by tables. Clin Orthop Relat Res 452: 216-224. [Crossref]

22. Ounpuu S, DeLuca P, Davis R, Romness M (2002) Long-term effects of femoral derotation osteotomies: an evaluation using three-dimensional gait analysis. J Pediatr Orthop 22: 139-145. [Crossref]

23. McCarthy J, Shrader WM, Graham K, Veerkamp M, Brower L, et al. (2020) Establishing surgical indications for hamstring lengthening and femoral derotational osteotomy in ambulatory children with cerebral palsy. J Child Orthop 14: 50-57. [Crossref]

24. Peacock WJ, Staudt LA (1990) Spasticity in cerebral palsy and the selective posterior rhizotomy procedure. J Child Neurol 5: 179-185. [Crossref]

25. De Vloo P, Huttunen TJ, Forte D, Jankovic I, Lee A, et al. (2020) Intraoperative electrophysiology during single-level selective dorsal rhizotomy: technique, stimulation threshold, and response data in a series of 145 patients. J Neurosurg Pediatr 2020: $1-10$. [Crossref]

26. Baker R, McGinley JL, Schwartz MH, Beynon S, Rozumalski A, et al. (2009) The gait profile score and movement analysis profile. Gait Posture 30: 265-269. [Crossref] 
27. Baker R, McGinley JL, Schwartz M, Thomason P, Rodda J, et al. (2012) The minimal clinically important difference for the Gait Profile Score. Gait Posture 35: 612-615. [Crossref]

28. Palisano R, Rosenbaum P, Walter S, Russell D, Wood E, et al. (1997) Development and reliability of a system to classify gross motor function in children with cerebral palsy. Dev Med Child Neurol 39: 214-223. [Crossref]

29. Graham HK, Harvey A, Rodda J, Nattrass GR, Pirpiris M (2004) The Functional Mobility Scale (FMS). J Pediatr Orthop 24: 514-520. [Crossref]

30. Novacheck TF, Stout JL, Tervo R (2000) Reliability and validity of the Gillette Functional Assessment Questionnaire as an outcome measure in children with walking disabilities. J Pediatr Orthop 20: 75-81. [Crossref]

31. Clavien PA, Barkun J, de Oliveira ML, Vauthey JN, Dindo D, et al. (2009) The ClavienDindo classification of surgical complications: five-year experience. Ann Surg 250: 187-196. [Crossref]

32. Zhou L, Willoughby K, Strobel N, Thomason P, Gallagher C, et al. (2018) Classifying adverse events following lower limb orthopaedic surgery in children with cerebral palsy: Reliability of the Modified Clavien-Dindo System. J Pediatr Orthop 38: e604 e609. [Crossref]

33. Thomas SS, Aiona MD, Pierce R, Piatt JH $2^{\text {nd }}$ (1996) Gait changes in children with spastic diplegia after selective dorsal rhizotomy. J Pediatr Orthop 16: 747-752. [Crossref]

34. O'Sullivan R, Leonard J, Quinn A, Kiernan D (2019) The short-term effects of selective dorsal rhizotomy on gait compared to matched cerebral palsy control groups. PLoS One 14: 0220119.

35. Cole GF, Farmer SE, Roberts A, Stewart C, Patrick JH (2007) Selective dorsal rhizotomy for children with cerebral palsy: the Oswestry experience. Arch Dis Child 92: 781-785. [Crossref]

36. McFall J, Stewart C, Kidgell V, Postans N, Jarvis S, et al. (2015) Changes in gait which occur before and during the adolescent growth spurt in children treated by selective dorsal rhizotomy. Gait Posture 42: 317-322. [Crossref]

37. Romei M, Oudenhoven LM, van Schie PEM, van Ouwerkerk WJR, van der Krogt MM, et al. (2018) Evolution of gait in adolescents and young adults with spastic diplegia after selective dorsal rhizotomy in childhood: A 10 year follow-up study. Gait Posture 64: 108-113. [Crossref]
38. Ounpuu S, Solomito M, Bell K, Pierz K (2017) Long-term outcomes of external femora derotation osteotomies in children with cerebral palsy. Gait Posture 56: 82-88. [Crossref]

39. Dreher T, Wolf SI, Heitzmann D, Swartman B, Schuster W, et al. (2012) Long-term outcome of femoral derotation osteotomy in children with spastic diplegia. Gait Posture 36: 467-470. [Crossref]

40. Sung KH, Kwon S-S, Chung CY, Lee KM, Cho GH, et al. (2018) Long-term outcomes over 10 years after femoral derotation osteotomy in ambulatory children with cerebral palsy. Gait Posture 64: 119-125. [Crossref]

41. Kwon DG, Lee SY, Kim TW, Chung CY, Lee KM, et al. (2013) Short-term effect of proximal femoral derotation osteotomy on kinematics in ambulatory patients with spastic diplegia. J Pediatr Orthop B 22: 189-194. [Crossref]

42. Thomas SS, Aiona MD, Buckon CE, Piatt JHJ (1997) Does gait continue to improve 2 years after selective dorsal rhizotomy? J Pediatr Orthop 17: 387-391. [Crossref]

43. Böhm H, Hösl M, Döderlein L (2017) Predictors for anterior pelvic tilt following surgical correction of flexed knee gait including patellar tendon shortening in children with cerebral palsy. Gait Posture 54: 8-14. [Crossref]

44. Steinbok P, Schrag C (1998) Complications after selective posterior rhizotomy for spasticity in children with cerebral palsy. Pediatr Neurosurg 28: 300-313. [Crossref]

45. Nordmark E, Josenby AL, Lagergren J, Andersson G, Stromblad L-G, et al. (2008) Long-term outcomes five years after selective dorsal rhizotomy. BMC Pediatr 8: 54. [Crossref]

46. Jeffery SMT, Markia B, Pople IK, Aquilina K, Smith J, et al. (2019) Surgical outcomes of single-level bilateral selective dorsal rhizotomy for spastic diplegia in 150 consecutive patients. World Neurosurg 125: e60-e66. [Crossref]

47. Erhaze EK, Dowling M, Devane D (2016) Parental presence at anaesthesia induction: A systematic review. Int J Nurs Pract 22: 397-407. [Crossref]

48. Hägglöf B (1999) Psychological reaction by children of various ages to hospital care and invasive procedures. Acta Paediatr Suppl 88: 72-78. [Crossref]

49. Bakri MH, Ismail EA, Ali MS, Elsedfy GO, Sayed TA, et al. (2015) Behavioral and emotional effects of repeated general anesthesia in young children. Saudi $J$ Anaesth 9: $161-166$.

Copyright: (C2021 Schreurs H. This is an open-access article distributed under the terms of the Creative Commons Attribution License, which permits unrestricted use, distribution, and reproduction in any medium, provided the original author and source are credited. 